\title{
PERPENDICULAR TURNING SOLAR TRACKER ANTI-COLLISION CAR
}

\author{
Sujash Dhole \\ Department of Electrical Engineering \\ Vellore Institute of Technology, Bhopal, MP, INDIA
}

\begin{abstract}
We could definitely make a flying car - but that's not the hard part. The hard part is, how do you make a flying car that is super safe and quiet?" - ELON MUSK
\end{abstract}

While safety, reliability, fuel economy, and low running costs put them at the top of the list of what people consider to be the 'most important' in a car, more than a third $(36 \%)$ of those tested online rank with the latest driving skills in the same fields. Driving technology includes steering or parking assist, adaptive cruise control, and wireless entry or ignition. More than a quarter $(28 \%)$ of people online also account for having the latest passenger technology, which includes audio or video streaming and social networking, as 'most important' to them. Our team has developed a vehicle archetype which is incorporated of Azimuth Angle, trimming off the turning radius and anti-collision mitigation system like concepts with a single touch button. The underlying concept of the smart car is to free the driver from many of the mundane tasks associated with driving, making the act of driving more pleasant.

Keywords-Solar Tracker, Solar azimuth angle, Turning radius, Motor control, Control unit.

\section{INTRODUCTION}

In such dense country like India accidents are like daily event so our idea will prove to be a mitigation for these kinds of problems. Once NDTV anchor released a report in which they have said about 1214 road crashes occur in a day in which one serious road accidents takes place. Also, area is also one of important parameter with respect to number of cars increasing day to day. The proposed system is Perpendicular Turning Solar Tracker Anti-Collision Car is just the right solution for the problems. Its Anti-Collision is also used to transmit infrared radiation. if there is an obstacle along the way, infrared rays are visible. this reflects the infrared radiation received by the receiver circuit, called the "IR receiver". Our model

\author{
Satyam Mehrotra \\ Department of Electrical Engineering \\ Vellore Institute of Technology, Bhopal, MP, INDIA
}

provides all these features under single control panel. Its solar system is fully automatic and changes its direction according to sun position with a fixed angle to extract most of the energy for its operation. In solar power plant, the tilt angle and the azimuth angle play an important role in plant performance. Therefore, it is very important to direct the solar panels with a tilt angle and azimuth angle to any given location. In addition, our model will also apply to operating in less space than a standard car by turning the whole car by cutting the turning ratio. Parking management includes integrated strategies for finding and parking prices in sustainable ways. It is designed to improve quality of life in urban spaces in sensitive city areas. As a result, we adopted perpendicular turning for consuming less area even at times of warren area situations.

\section{EXISTING ALGORITHM}

\section{A. Perpendicular turning -}

As we know that turning the car correctly not only plays an important role in driving but also while parking the car. There were several project and modification done in automobile industry to make this experience better, one of them was in Cadillac 1950 model. In this they use the spare wheel as a fifth wheel to turn the car they called this device the park car [1]. But the problem with this device is that as the spare wheel is only used while the operation of this device it under goes lot of wear and tear, it took most of the truck space and now your spare wheel is not available any more during the need.

\section{B. Solar tracker}

In today's advancement in technology the reduction in energy consumption has become an important element in automobile industry. As we are moving toward electric and hybrid vehicle energy utilization is the key feature. In this many industries like Hyundai, Tesla etc. had come up with the solar roof [2-3] on their electric car but they did not consider the azimuth angle in that arrangement which make it inefficient. However, throughout the year the pattern of the sun and the height of the sun vary. 


\section{International Journal of Engineering Applied Sciences and Technology, 2021 \\ Vol. 5, Issue 9, ISSN No. 2455-2143, Pages 169-172 \\ Published Online January 2021 in IJEAST (http://www.ijeast.com)}

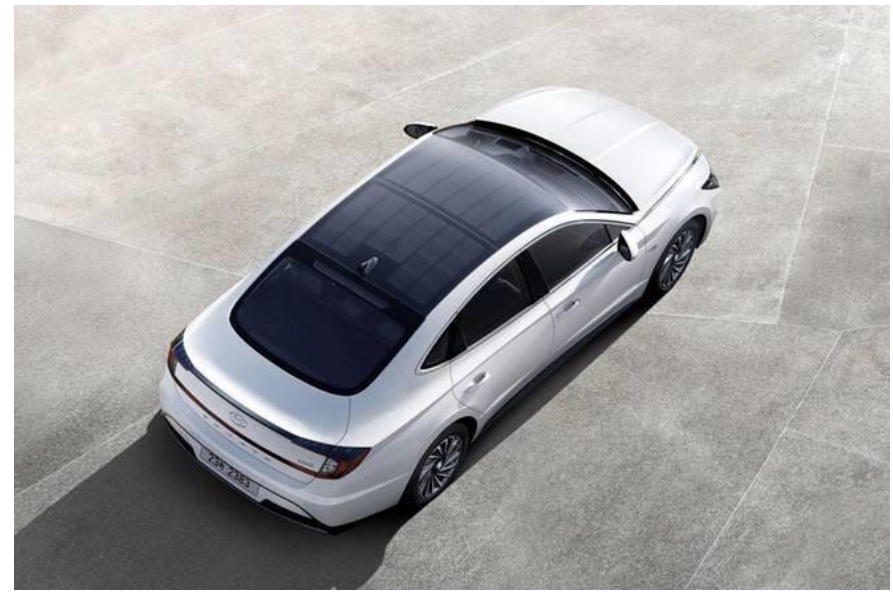

Fig. 1. Hyundai Sonata Hybrid with solar-panel roof.

\section{PROPOSED ALGORITHM}

\section{A. Perpendicular Turning -}

In our model we will control the wheel's axel that ones the car goes to perpendicular turning mode. The wheel would come out perpendicularly, now if we accelerate the car it would move the left and right rather forward or backward.
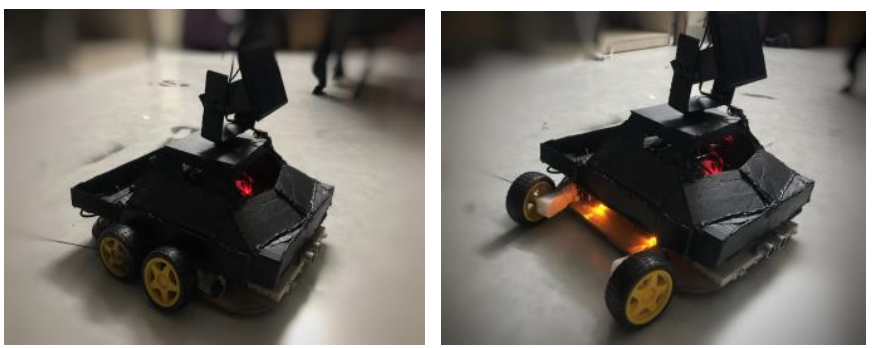

Fig. 2. The model of the car (a. the car in its normal mode b. the car in its parking or turning mode)

The above model of car not only has the convectional turning [4-6] but this new arrangment have let the car for a new turning which we call the perpendicular turning. This new turning rules out the problem of turning radius in the convection systems. Now our vehicle could be park in accesible garages. Because parking solutions are not the end in themselves, but rather a means of achieving greater social goals in order to improve urban transport and make cities more accessible and efficient, this paper also discusses the environmental impacts that need to be considered for the proposed solutions.

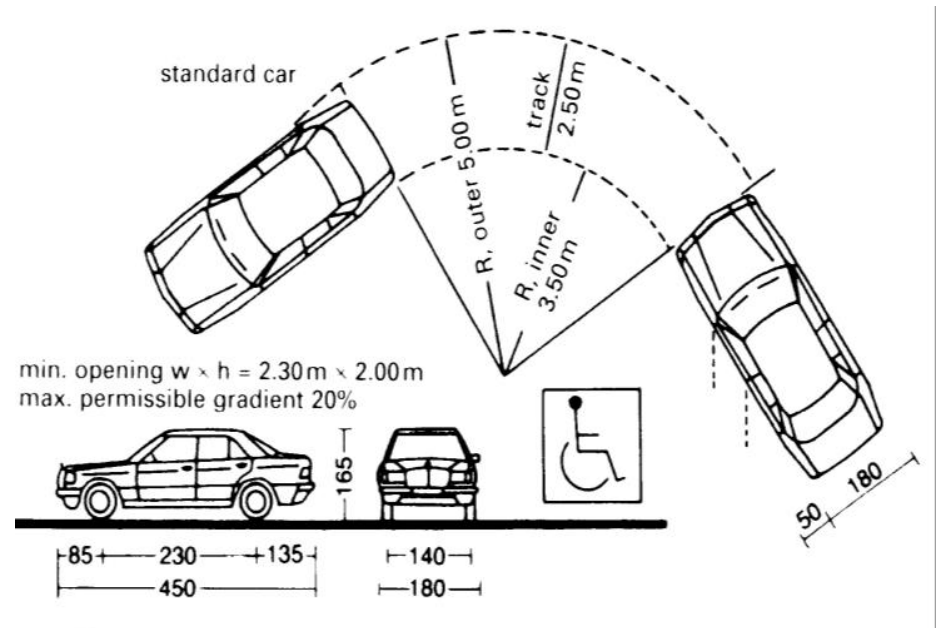

Fig. 3. Turning radius of cars

\section{B. Solar Tracker -}

As we have already mentioned about the azimuth angle. It is the compass direction from which the sun is coming. This azimuth angle plays an important if we have to extract the maximum energy from the sun [7-8]. For most of the areas in UK if solar panel are installed at $-4^{\circ}$ and $+2^{\circ}$ we will have maximum energy production. Putting the panel at right azimuth angle increse the total production by $16 \%$. But it not possible for a automobile industry to calclate the solar azimuth angle for all the place and manufacture the vehicle accordingly.

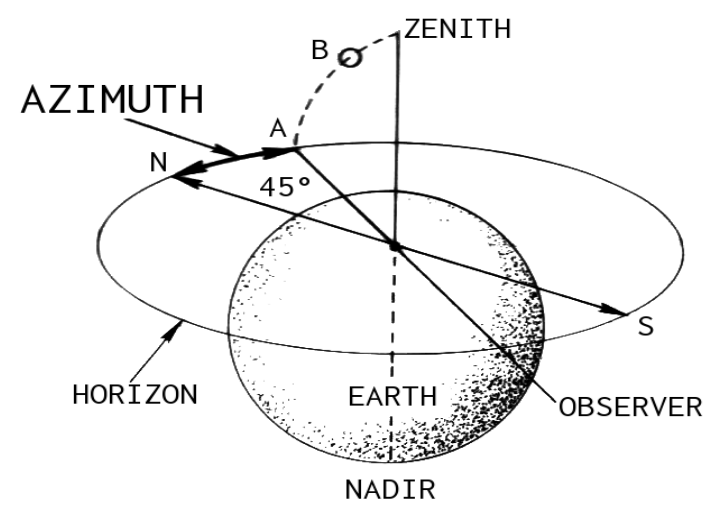

Fig. 4. Showing the azimuth angle for a region

So, in our model we have overcome the problem by just a simple solution which allow the panel to automatically adjust it where there is more sunlight. 


\section{WORKING}

\section{A. Perpendicular Turning -}

For moving the wheels perpendicularly, the main problem was the wheel's axel [9-12]. For this the wheel in are model are controlled independently. We are using the vertical axel which provide the independent control to wheel. The independent control is also important because the four wheel which are Front left, Front right, Rear left and Rear right in normal mode are now Rear left, Front left, Rear right and Rear left respectively once the parking or turning mode is ON. For this we have put a control unit which is programmed to change the direction of wheel spin also. So, once the driver pushes the parking mode button in his/her vehicle two things took place first a motor control turns the main parking motor $90^{\circ}$ which bring all the wheels pedicular to the vehicle and at the same time the control unit change the spin if the wheel so that the vehicle could move. During the time vehicle is operated in parking or turning mode the assistant light will also turn ON. Since the weight of the vehicle get distributed over all the wheel which overcome the problem faced in the Cadillac model.

\section{$B$. Solar Tracker -}

We continuous and constant monitoring of the sun's position throughout daytime and when the tracker is subjected to the darkness it stops or sleeps according to its design. This can be done using of photosensitive sensors, like photoresistors (LDRs) whose voltage output are input into a microcontroller which then drive actuators (motors) to regulate the position of the solar panel. For more accurate positioning of panel, we will use two axel which would turn the panel in any direction, to achieve this setup we have used six LDRs placed at different position. In this model we have uses a cadmium sulfidic (CdS) photocell for light sensing. It is a passive component whose resistance in inversely proportional to the amount of light intensity falling on it. A voltage divider is thus formed and the output at the junction is determined by the two resistances. In this project, it was desired for the output voltage to increase as the light intensity increases and thus the panel automatically adjust itself where the sunlight is more which automatically increase the energy efficiency of the vehicle.

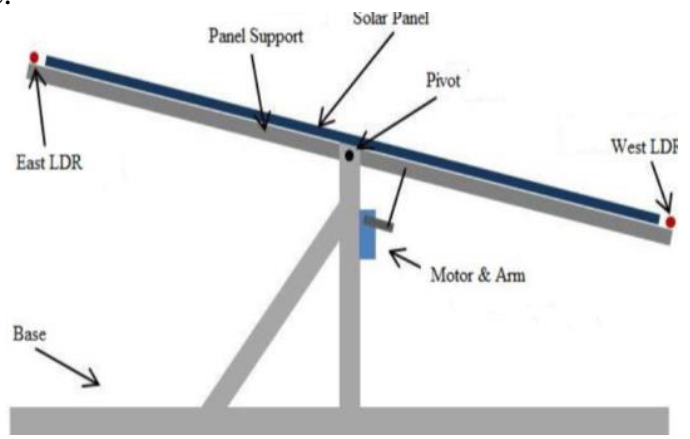

Fig. 5. Single axis solar tracker

\section{FUTURE SCOPE}

There is always room for improvement in all applications or an industrial practice practiced in the world but which is necessary keeping the practice as simple as possible to a nontechnical user with no technology Information about the field can embrace our practice.

In the future we may start to use the concept of sensory sensitivity in weather conditions as the weather can adversely affect sensory performance in AVs, which may impede reception. Secondly, we will work to connect its work via mobile phone so that it can work more easily and add better communication through the use of algorithms to reduce latency and speed up response. And hackers are notorious for using public WIFI and injecting malware to steal personal information. This is a growing public concern when it comes to private cars. So, looking at this section, we will include consumer security encryption. Private cars will benefit from smart cities in their quest for complete automation. Instead of private cars just communicating with each other, they will be able to communicate with smart devices built in smart cities too. For example, intelligent robots will be able to better control the flow of traffic. So, we're going to work again in that field.

\section{CONCLUSION}

"Healing the world is the basis cultivation with which the hour clock is calling and this project presents the eye, therefore, to open the corridors of reducing the amount of pollution in storing of energy culled out from the Sun and also to make the pace of advancement revved around. "

The hybrid car concept is designed by us and is of a high standard and after this our endeavour is to project a indigenous hybrid car concept in India that particular has benefited. This solstice is a solvent single solvent of so many available socioeosonomic problems such as pollution, energy shortage and parking shortage. The conversation has been posted to this car such as wind turbine, solar energy deviance, autonomous sensitivity concept are made uniquely and also state of the art in particular. It also combats the problems faced during the parking in constrained parking spaces. It gives time pixel transitions give you a better chance of using power while processing.

Moreover, the compounds used in this program are probably the most efficient, the material used is possible, inexpensive and very fast in the market. The assembly system is simple and light and can be installed on all sections of car well.

\section{REFERENCE}

[1] Jejukar A. S. Kurkure G. C., Parallel Parking of Car using fifth wheel, International Journal of Innovative and 


\section{International Journal of Engineering Applied Sciences and Technology, 2021 \\ Vol. 5, Issue 9, ISSN No. 2455-2143, Pages 169-172 \\ Published Online January 2021 in IJEAST (http://www.ijeast.com)}

Emerging Research in Engineering Volume 4, Special Issue 1, NCIAR, 2017, pp.105-107.

[2] Georgiev.R.A., Boudinov.A., and Cheap.H. 2005. "Two axis sun following device." Energy conservation and management 46:1179-92

[3] Dhanabal.R., Bharathi.V., Ranjitha.R., Ponni.A., Deepthi.S., and Mageshkannan.P. 2013. "Comparison of efficiencies of solar tracker systems with static panel single axis tracking system and dual axis tracking system with fixed mount." International Journal of Engineering and Technology (IJET) 5:1925-1933.

[4] Vlk F., "Dynamika motorových vozidel", Nakladatelství a zasilatelství VLK, Brno, 2001.

[5] Gupta R. B., "Automobile Engineering, Satya Prakashan", New Delhi, pp 3-8 and 571-579, 2007.

[6] Cho Y.G. "Vehicle steering returnability with maximum steering wheel angle at low speeds", International Journal of Automotive Technology, 10(4), pp 431-439, 2009.

[7] Basore P.A.: Manufacturing a New Polycrystalline Silicon PV Technology, Conference Record of the 2006 IEEE 4th World Conference on Photovoltaic Energy Conversion, pp. 2089-2093, 2006.

[8] Zhang Q.X., Yu H.Y., Zhang Q.Y., Zhang Z.Y., Shao C.H., and Yang D., "A solar automatic tracking system that generates power for lighting greenhouses," Energies, vol. 8(7), pp. 7367-7380, 2015.

[9] Dhande K.V, Ulhe P. "Design and Analysis of Front axle of Heavy Commercial Vehicle", International Journal of Science, Technology and Management Volume No.03, Issue No. 12,December 2014

[10] Dey Shidarth , P.R.V.V.V Sri Rama Chandra Murthy. D, P. Baskar "Structural Analysis of Front axle beam of a Light Commercial Vechicle (LCV)", International Jounral of Engineering Treads and Technology (IJETT)- Volume 11 Number 5-May 2014

[11] Patil M N, Shreepad Sarange "Finite Element Analysis of Von Mises Stress \& Deformtion at Tip of Cutting Tool", International Jounral of Innovation Research in Advanced Engineering, Volume 1 Issue 1 (April 2014)

[12] Pokorny, P., Nahlik, L, Hutar, P. "Comparosion of different load spectra on residual fatigue lifetime of railway axle", Procedia engineering 74(2014) 313-316
[13] Byers, T.J., 1988. 20 selected solar projects making sun tracking based on type of microcontroller LM324N. photovoltaics work for you. translated from Eng. Mir, This article has shown, the development and Moscow, pp: 196

[14] Byers, T.J., 1988. 20 selected solar projects making sun tracking based on type of microcontroller LM324N. photovoltaics work for you. translated from Eng. Mir, This article has shown, the development and Moscow, pp: 196 